\title{
Prognostic Value of Metabolic Tumor Volume and Total Lesion Glycolysis in Head and Neck Cancer: A Systematic Review and Meta-Analysis
}

\author{
Kyoungjune Pak ${ }^{1-3}$, Gi Jeong Cheon ${ }^{1,4}$, Hyun-Yeol Nam ${ }^{5}$, Seong-Jang Kim ${ }^{2,3}$, Keon Wook Kang ${ }^{1,4}$, June-Key Chung ${ }^{1,4}$, \\ E. Edmund $\mathrm{Kim}^{6,7}$, and Dong Soo Lee ${ }^{1,4,6}$ \\ ${ }^{1}$ Department of Nuclear Medicine, Seoul National University Hospital, Seoul, Korea; ${ }^{2}$ Department of Nuclear Medicine, Pusan \\ National University Hospital, Busan, Korea; ${ }^{3}$ Medical Research Institute, Pusan National University Hospital, Busan, Korea; \\ ${ }^{4}$ Cancer Research Institute, Seoul National University Hospital, Seoul, Korea; ${ }^{5}$ Department of Nuclear Medicine, Samsung \\ Changwon Hospital, Sungkyunkwan University School of Medicine, Changwon, Korea; ${ }^{6}$ WCU Graduate School of Concergence \\ Science and Technology, Seoul National University College of Medicine, Seoul, Korea; and ${ }^{7}$ University of California at \\ Irvine, Irvine, California
}

We conducted a comprehensive systematic review of the literature on volumetric parameters and a meta-analysis of the prognostic value of metabolic tumor volume (MTV) and total lesion glycolysis (TLG) in patients with head and neck cancer (HNC). Methods: A systematic search of MEDLINE and EMBASE was performed using the key words PET, head and neck, and volume. Inclusion criteria were ${ }^{18} \mathrm{~F}-\mathrm{FDG}$ PET used as an initial imaging tool; studies limited to HNC; patients who had not undergone surgery, chemotherapy, or radiotherapy before PET scans; and studies reporting survival data. Event-free survival and overall survival were considered markers of outcome. The impact of MTV or TLG on survival was measured by the effect size hazard ratio (HR). Data from each study were analyzed using Review Manager. Results: Thirteen studies comprising 1,180 patients were included in this study. The combined HR for adverse events was 3.06 (2.33-4.01, $P<0.00001)$ with MTV and 3.10 (2.27-4.24, $P<0.00001)$ with TLG, meaning that tumors with high volumetric parameters were associated with progression or recurrence. Regarding overall survival, the pooled HR was 3.51 (2.62-4.72, $P<0.00001$ ) with MTV and 3.14 (2.24-4.40, $P<$ $0.00001)$ with TLG. There was no evidence of significant statistical heterogeneity at an $\mathrm{I}^{2}$ of $0 \%$. Conclusion: MTV and TLG are prognostic predictors of outcome in patients with HNC. Despite clinically heterogeneous HNC and the various methods adopted between studies, we can confirm that patients with a high MTV or TLG have a higher risk of adverse events or death.

Key Words: PET; volume; head and neck; cancer

J Nucl Med 2014; 55:1-7

DOI: 10.2967/jnumed.113.133801

H ead and neck cancer (HNC) includes malignancies of the oral cavity, oropharynx, hypopharynx, larynx, sinonasal tract, and

Received Oct. 11, 2013; revision accepted Jan. 29, 2013.

For correspondence or reprints contact: Gi Jeong Cheon, Department of Nuclear Medicine, Seoul National University Hospital, 101 Daehak-ro, Jongno-gu, Seoul, 110-744, Korea.

E-mail: Korea, larrycheon@gmail.com

Published online ...........

COPYRIGHT (C 2014 by the Society of Nuclear Medicine and Molecular Imaging, Inc. nasopharynx (1). HNCs are histologically identical but clinically heterogeneous entities that show disparities in natural course or clinical behavior based on primary location (2). The American Joint Committee on Cancer staging is generally used to estimate the prognosis and guide therapy. However, the prognostic value of American Joint Committee on Cancer staging is limited in individual patients in the pretreatment stage, because staging is based on tumor morphology and does not reflect individual biologic and molecular markers (1).

PET using ${ }^{18}$ F-FDG has become a standard modality for staging, restaging, and monitoring the treatment response in a variety of tumors (3). In addition, it is more accurate than conventional staging in HNC, overcoming the limitations of morphologic imaging modalities (1). Standardized uptake value (SUV) is a semiquantitative measure of the normalized concentration of radioactivity in a lesion, and maximum SUV (SUVmax) is one of the most widely used parameters in clinical practice (1). However, SUVmax shows the highest intensity of ${ }^{18}$ F-FDG uptake within the region of interest or volume of interest (VOI) and cannot represent total tumor uptake for the entire tumor mass (3).

Recently, there has been an increasing interest in the use of volumetric parameters of metabolism such as metabolic tumor volume (MTV) and total lesion glycolysis (TLG). MTV and mean SUV can be measured by contouring margins defined by thresholds. Then, TLG can be calculated by multiplying MTV by mean SUV, which weights the volumetric burden and metabolic activity of tumors (3-5). Commercially available tools for tumor analysis enable rapid and easier measurement of MTV or TLG (3). These parameters could be used to reflect disease burden and tumor aggressiveness in some kinds of malignant tumors (6). However, there have been conflicting results regarding the prognostic value of volumetric parameters in $\operatorname{HNC}(7,8)$. Thus, we conducted a comprehensive systematic review of the literature on volumetric parameters and designed a meta-analysis to assess the prognostic value of MTV and TLG in patients with HNC.

\section{MATERIALS AND METHODS}

\section{Data Search and Study Selection}

We performed a systematic search of MEDLINE (inception to July 2013) and EMBASE (inception to July 2013) for English publications using the key words PET, head and neck, and volume. All searches were 
limited to human studies. Inclusion criteria were ${ }^{18} \mathrm{~F}-\mathrm{FDG}$ PET used as an initial imaging tool; studies limited to HNC; patients who had not undergone surgery, chemotherapy, or radiotherapy before PET scans; and studies that reported survival data. Reviews, abstracts, and editorial materials were excluded. Two authors conducted the searches and screening independently. Any discrepancies were resolved by a consensus.

\section{Data Extraction and Quality Assessment}

Data were extracted from the publications independently by 2 reviewers, and the following information was recorded: first author, year of publication, country, PET machine, study design, number of patients, types of diseases, staging, treatment, and endpoints. Three reviewers scored each publication according to a quality scale, which was based on that used in previous studies $(9,10)$. This quality scale was grouped into 4 categories: scientific design, generalizability, analysis of results, and PET reports. A value between 0 and 2 was attributed to each item. Each category had a maximum score of 10 points. The scores were expressed as a percentage of the maximum 40 points.

\section{Statistical Analysis}

The primary outcome was event-free survival (EFS). Disease-free survival, locoregional control, and progression-free survival were obtained as primary outcomes and newly defined as EFS, which was measured from the date of initiation of therapy to the date of recurrence or metastasis (11). The secondary endpoint was overall survival (OS), defined as the time from initiation of therapy until death by any cause. The impact of MTV or TLG on survival was measured by the effect size of hazard ratio (HR). Survival data were extracted using the following methodology suggested by Parmar et al. (12). We extracted a univariate HR estimate and $95 \%$ confidence intervals (CIs) directly from each study if provided by the authors. Otherwise, $P$ values of the log-rank test, $95 \% \mathrm{CI}$, number of events, and number at risk were extracted to estimate the HR indirectly. Survival rates on the graphical representation of the Kaplan-Meier curves were read by Engauge Digitizer (version 3.0; http://digitizer. sourceforge.net) to reconstruct the HR estimate and its variance, assuming that patients were censored at a constant rate during the follow-up. An HR greater than 1 implied worse survival for patients with a high MTV or TLG, whereas an HR less than 1 implied a survival benefit for patients with a high MTV or TLG. Heterogeneity between studies was assessed by $\chi^{2}$ test and $\mathrm{I}^{2}$ statistics, as described by Higgins et al. (13). Funnel plots were used to assess publication bias graphically (14). We also extracted survival data of SUVmax from the same studies included in this meta-analysis as mentioned above. $P$ values of less than 0.05 were considered statistically significant. Data from each study were analyzed using Review Manager (RevMan, version 5.2; The Nordic Cochrane Centre, The Cochrane Collaboration).

\section{RESULTS}

\section{Study Characteristics}

The electronic search identified 365 articles. After the exclusion of non-English articles $(n=24)$, conference abstracts $(n=131)$, and 180 studies that did not meet the inclusion criteria based on title and abstract, and reviewing the full text of 30 articles, 13 studies including 1,180 patients were eligible for this study. The detailed

[Fig. 1] procedure is presented in Figure 1. Three of 13 studies were of a prospective design. The studies included malignancies of the oral cavity, nasopharynx, oropharynx, hypopharynx, larynx, or salivary gland. Either MTV (2,15-17) or TLG (18) was measured in 5 studies, and both were measured in 8 studies $(8,19-25)$. The VOI was defined as the tumor $(2,8,17-23)$ or tumor plus metastatic lymph nodes (LNs) $(15,16,24,25)$. Three threshold methods were adapted to segment VOIs. A fixed SUV of $2.5(2,8,15-19,22)$ or 3.0 (23) was used in 9 studies. The gradient segmentation method was applied in 1 study (20), and a percentage of SUVmax (30\%, 42\%, or $50 \%$ ) was used in 3 studies $(21,24,25)$. In each study, patients were divided into 2 groups (high and low volume) based on cutoff values. A minimum $P$ value was used in 4 studies $(15,16,19,22)$, receiveroperating characteristics (ROCs) in 4 studies $(2,7,23,24)$, and median value in 5 studies $(16,18,20,21,23)$. High volumetric parameters were significant variables in predicting a worse prognosis except in 1 study (20). The cutoff values of MTV ranged between 7.7 and $45 \mathrm{~cm}^{3}$ and those of TLG ranged from 55 to 330 . The mean quality score was $79.4 \%$, ranging from $70 \%$ to $85 \%$. Visual inspection of the funnel plot suggested no evidence of publication bias. Study characteristics are summarized in Table 1.

[Table 1]

\section{Primary Outcome: EFS}

The EFS was analyzed using 8 studies with MTV. We performed subgroup analyses according to the definition of VOI. The HR for adverse events was 3.03 (95\% CI, 2.22-4.13; $P<$ $0.00001)$ for an MTV defined by the tumor and 3.15 (95\% CI, $1.80-5.51, P<0.0001$ ) for an MTV defined by the tumor and LN. The combined HR was 3.06 (95\% CI, 2.33-4.01, $P<0.00001)$. The test for heterogeneity gave no significant results $\left(\chi^{2}=3.40\right.$, $\left.P=0.85 ; \mathrm{I}^{2}=0 \%\right)$. Five studies with TLG were included in the second analysis of EFS. When a fixed-effect model was used, the pooled HR was 3.10 (95\% CI, 2.27-4.24, $P<0.00001$; $\left.\mathrm{I}^{2}=0 \%\right)$, meaning that tumors with a high TLG are associated with progression and recurrence. Forest plots of MTV and TLG are shown in Figures 2 and 3, respectively.

Additional subgroup analyses were performed according to tumor delineation, cutoff values, and study design (Table 2). Among stud- [Table 2] ies including MTV, those with a fixed SUV of 2.5 had an HR of 3.17 (95\% CI, 2.30-4.36, $P<0.00001$ ), and those with other thresholds had an HR of 2.78 (95\% CI, 1.66-4.66, $P=0.0001)$. Studies with cutoff values using ROC had an HR of 4.30 (95\% CI, 2.46-7.54, $P<0.00001$ ), and those adopted cutoff values using other methods had an HR of 2.75 (95\% CI, 2.02-3.75, $P<0.00001)$. Among studies including TLG, those with a fixed SUV of 2.5 had an HR of 3.45 (95\% CI, 2.33-5.12, $P<0.00001$ ), and those with other thresholds had an HR of 2.59 (95\% CI, 1.55-4.31, $P=0.0003$ ).

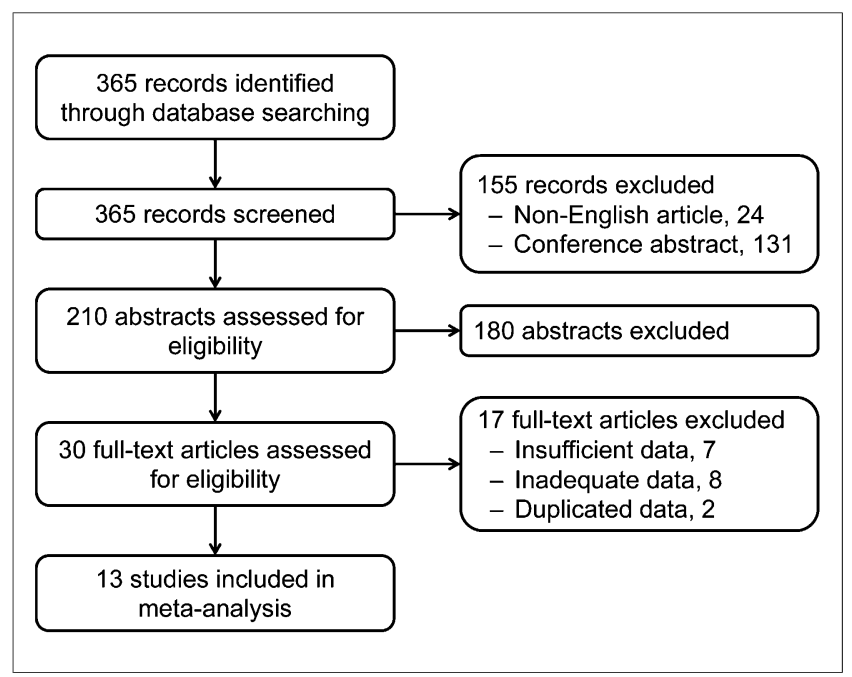

FIGURE 1. Flowchart of study selection. 




MTV and TLG in Head And Neck CAnCer - Pak et a 


\begin{tabular}{|c|c|c|c|c|c|c|c|c|}
\hline Study or subgroup & $\log [$ hazard ratio] & SE & Weight & $\begin{array}{l}\text { Hazard ratio } \\
\mathrm{IV} \text {, fixed, } 95 \% \mathrm{Cl}\end{array}$ & Year & \multicolumn{3}{|c|}{$\begin{array}{l}\text { Hazard ratio } \\
\text { IV, fixed, } 95 \% \mathrm{CI}\end{array}$} \\
\hline \multicolumn{9}{|l|}{ 1.1.1 tumor } \\
\hline Xie P & 1.2296 & 0.5014 & $7.6 \%$ & $3.42[1.28,9.14]$ & 2010 & & & \\
\hline Chan SC & 1.2238 & 0.2759 & $25.3 \%$ & $3.40[1.98,5.84]$ & 2011 & & $\varpi-$ & \\
\hline $\mathrm{KaO} \mathrm{CH}$ & 1.0080 & 0.3923 & $12.5 \%$ & $2.74[1.27,5.91]$ & 2012 & & & \\
\hline Park GC & 1.4770 & 0.4481 & $9.6 \%$ & $4.38[1.82,10.54]$ & 2012 & & & \\
\hline $\begin{array}{l}\text { Abd El-Hafez YG } \\
\text { Subtotal ( } 95 \% \mathrm{Cl})\end{array}$ & 0.8198 & 0.3003 & $\begin{array}{l}21.3 \% \\
76.3 \%\end{array}$ & $\begin{array}{l}2.27[1.26,4.09] \\
3.03[2.22,4.13]\end{array}$ & 2013 & & $\Longrightarrow-$ & \\
\hline \multicolumn{9}{|c|}{$\begin{array}{l}\text { Heterogeneity: } X^{2}=1.90, \mathrm{df}=4(P=0.75) ; 1^{2}=0 \% \\
\text { Test for overall effect: } Z=6.98(P<0.00001)\end{array}$} \\
\hline \multicolumn{9}{|l|}{ 1.1.2 tumor $+\mathrm{LN}$} \\
\hline Chung MK & 1.0578 & 0.5296 & $6.9 \%$ & $2.88[1.02,8.13]$ & 2009 & & & \\
\hline Kim G & 0.8717 & 0.4262 & $10.6 \%$ & $2.39[1.04,5.51]$ & 2011 & & & \\
\hline $\begin{array}{l}\text { Ryu IS } \\
\text { Subtotal }(95 \% \mathrm{Cl})\end{array}$ & 1.7138 & 0.5550 & $\begin{array}{r}6.2 \% \\
23.7 \%\end{array}$ & $\begin{array}{r}5.55[1.87,16.47] \\
\mathbf{3 . 1 5}[\mathbf{1 . 8 0}, \mathbf{5 . 5 1}]\end{array}$ & 2013 & & & \\
\hline \multicolumn{9}{|c|}{$\begin{array}{l}\text { Heterogeneity: } X^{2}=1.49, \mathrm{df}=2(P=0.48) ; 1^{2}=0 \% \\
\text { Test for overall effect: } Z=4.03(P<0.00001)\end{array}$} \\
\hline Total $(95 \% \mathrm{Cl})$ & & & $100.0 \%$ & $3.06[2.33,4.01]$ & & & & \\
\hline \multicolumn{5}{|c|}{$\begin{array}{l}\text { Heterogeneity: } X^{2}=3.40, \mathrm{df}=7(P=0.85) ; l^{2}=0 \% \\
\text { Test for overall effect: } Z=8.06(P<0.00001) \\
\text { Test for subgroup differences: } X^{2}=0.01, \mathrm{df}=1(P=0.90) ; 1^{2}=0 \text { \% }\end{array}$} & & $0.05 \quad 0.2$ & 5 & 20 \\
\hline
\end{tabular}

FIGURE 2. Forest plots of HR for events with MTV.

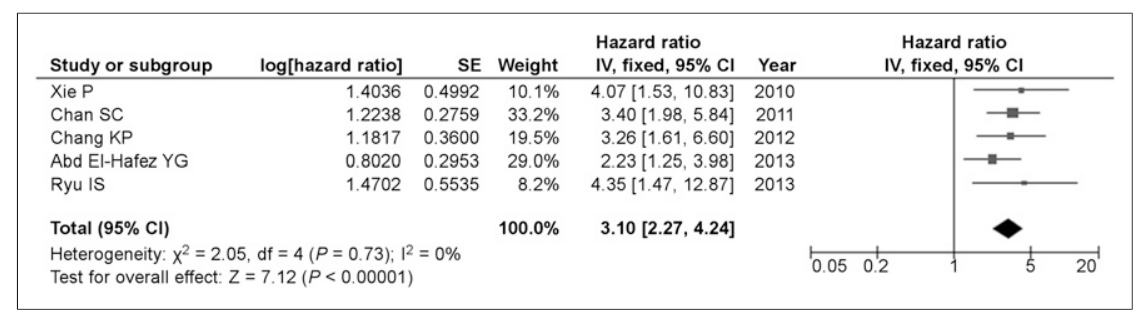

FIGURE 3. Forest plots of HR for events with TLG.

\section{Secondary Outcome: OS}

The survival analysis was based on 8 studies including MTV. Subgroup analysis was assessed according to the VOI of MTV. The HR for an MTV defined by the tumor was 3.19 (95\% CI, 2.28-
4.48; $P<0.00001)$ and that defined by the tumor and LN was 4.71 (95\% CI, 2.60-8.54, $P<0.00001)$. The combined HR was 3.51 (95\% CI, 2.62-4.72, $P<0.00001$ ) (Fig. 4). [Fig. 4] The test for heterogeneity gave no significant results $\left(\chi^{2}=5.71, P=0.57 ; \mathrm{I}^{2}=0 \%\right)$. Six studies with TLG were included in the analysis of OS. The pooled HR of death was 3.14 (95\% CI, 2.24-4.40, $P<0.00001$ ) (Fig. 5). [Fig. 5] There was no evidence of significant statistical heterogeneity, with an $\mathrm{I}^{2}$ of $0 \%\left(\chi^{2}=3.65\right.$, $P=0.60)$.

Additional subgroup analyses were performed according to tumor delineation and cutoff values (Table 2). Among studies of MTV, those with a fixed SUV of 2.5 had an HR of 4.09 (95\% CI, 2.63-6.36, $P<$ 0.00001 ), and those with other thresholds had an HR of 3.23 (95\% CI, 1.95-5.34, $P<0.00001)$. Studies with cutoff values using ROC had an HR of 4.57 (95\% CI, 2.89$7.25, P<0.00001)$, and those adopting cutoff values using other methods had $(95 \% \mathrm{CI}$, an HR of 2.93 (95\% CI, 2.0-4.29, $P<0.00001$ ). Among the studies including TLG, those with a fixed SUV of 2.5 had an HR of $3.90(95 \%$ CI, 2.45-6.21, $P<0.00001$ ), and those with other thresholds had an HR of $2.46(95 \% \mathrm{CI}$, $1.51-4.02, P=0.0003)$.

\section{Combined Data of SUVmax}

Survival data of SUVmax were extracted from 7 studies $(2,14$ $16,18,22,23)$ for EFS and from 3 studies $(2,18,23)$ for OS. The HR for adverse events was 1.83 (95\% CI, 1.39-2.42, $P<0.0001)$, and the test

TABLE 2

Subgroup Analyses

\begin{tabular}{|c|c|c|c|c|c|c|c|}
\hline Endpoint & Volumetric parameters & Factor & No. of studies & HR & $95 \% \mathrm{Cl}$ of $\mathrm{HR}$ & Heterogeneity, $\mathrm{I}^{2}(\%)$ & Model used \\
\hline \multirow[t]{6}{*}{ EFS } & MTV & VOI: & & & & & \\
\hline & & - Tumor & 5 & 3.03 & $2.22-4.13$ & 0 & Random effects \\
\hline & & - Tumor + LN & 3 & 3.15 & $1.80-5.51$ & 0 & Fixed effect \\
\hline & & $\begin{array}{l}\text { Tumor delineation: } \\
\text { - Fixed SUV2.5 } \\
\text { - Others }\end{array}$ & $\begin{array}{l}6 \\
2\end{array}$ & $\begin{array}{l}3.17 \\
2.78\end{array}$ & $\begin{array}{l}2.30-4.36 \\
1.66-4.66\end{array}$ & $\begin{array}{c}0 \\
50\end{array}$ & $\begin{array}{c}\text { Random effects } \\
\text { Fixed effect }\end{array}$ \\
\hline & & $\begin{array}{l}\text { Cutoff values: } \\
\text { - ROC } \\
\text { - Others }\end{array}$ & $\begin{array}{l}3 \\
5\end{array}$ & $\begin{array}{l}4.30 \\
2.75\end{array}$ & $\begin{array}{l}2.46-7.54 \\
2.02-3.75\end{array}$ & $\begin{array}{l}0 \\
0\end{array}$ & $\begin{array}{c}\text { Fixed effect } \\
\text { Random effects }\end{array}$ \\
\hline & TLG & $\begin{array}{l}\text { Tumor delineation: } \\
\text { - Fixed SUV2.5 } \\
\text { - Others }\end{array}$ & $\begin{array}{l}3 \\
2\end{array}$ & $\begin{array}{l}3.45 \\
2.59\end{array}$ & $\begin{array}{l}2.33-5.12 \\
1.55-4.31\end{array}$ & $\begin{array}{c}0 \\
12\end{array}$ & $\begin{array}{l}\text { Fixed effect } \\
\text { Fixed effect }\end{array}$ \\
\hline \multirow[t]{4}{*}{ OS } & MTV & $\begin{array}{l}\text { VOI: } \\
\text { - Tumor } \\
\text { - Tumor + LN }\end{array}$ & $\begin{array}{l}6 \\
2\end{array}$ & $\begin{array}{l}3.19 \\
4.71\end{array}$ & $\begin{array}{l}2.28-4.48 \\
2.60-8.54\end{array}$ & $\begin{array}{l}0 \\
0\end{array}$ & $\begin{array}{l}\text { Random effects } \\
\text { Fixed effect }\end{array}$ \\
\hline & & $\begin{array}{l}\text { Tumor delineation: } \\
\text { - Fixed SUV2.5 } \\
\text { - Others }\end{array}$ & $\begin{array}{l}4 \\
4\end{array}$ & $\begin{array}{l}4.09 \\
3.23\end{array}$ & $\begin{array}{l}2.63-6.36 \\
1.95-5.34\end{array}$ & $\begin{array}{c}0 \\
32\end{array}$ & $\begin{array}{l}\text { Random effects } \\
\text { Random effects }\end{array}$ \\
\hline & & $\begin{array}{l}\text { Cutoff values: } \\
\text { - ROC } \\
\text { - Others }\end{array}$ & $\begin{array}{l}4 \\
4\end{array}$ & $\begin{array}{l}4.57 \\
2.93\end{array}$ & $\begin{array}{c}2.89-7.25 \\
2.0-4.29\end{array}$ & $\begin{array}{l}0 \\
0\end{array}$ & $\begin{array}{l}\text { Random effects } \\
\text { Random effects }\end{array}$ \\
\hline & TLG & $\begin{array}{l}\text { Tumor delineation: } \\
\text { - Fixed SUV2.5 } \\
\text { - Others }\end{array}$ & $\begin{array}{l}3 \\
3\end{array}$ & $\begin{array}{l}3.90 \\
2.46\end{array}$ & $\begin{array}{l}2.45-6.21 \\
1.51-4.02\end{array}$ & $\begin{array}{l}0 \\
0\end{array}$ & $\begin{array}{l}\text { Fixed effect } \\
\text { Fixed effect }\end{array}$ \\
\hline
\end{tabular}




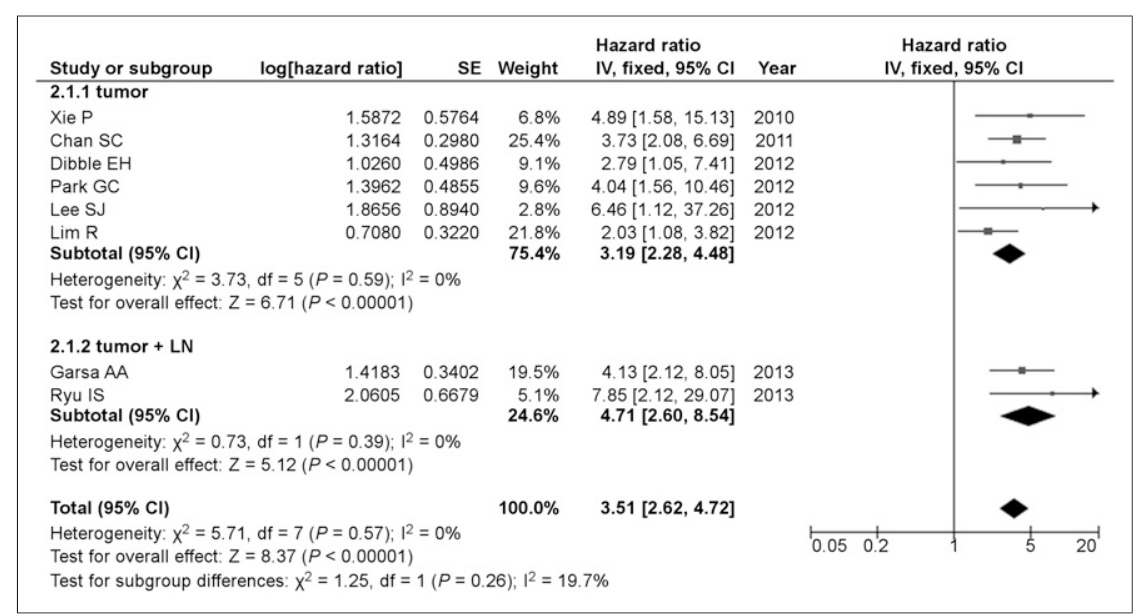

FIGURE 4. Forest plots of HR for deaths with MTV.

\begin{tabular}{|c|c|c|c|c|c|c|c|c|}
\hline Study or subgroup & log[hazard ratio] & SE & Weight & $\begin{array}{l}\text { Hazard ratio } \\
\text { IV, fixed, } 95 \% \mathrm{CI}\end{array}$ & Year & \multicolumn{3}{|c|}{$\begin{array}{c}\text { Hazard ratio } \\
\text { IV, fixed, } 95 \% \mathrm{CI}\end{array}$} \\
\hline Xie P & 1.7834 & 0.5771 & $8.9 \%$ & $5.95[1.92,18.44]$ & 2010 & & & \\
\hline Chan SC & 1.3164 & 0.2980 & $33.4 \%$ & $3.73[2.08,6.69]$ & 2011 & & -- & \\
\hline Dibble EH & 0.8755 & 0.5004 & $11.8 \%$ & $2.40[0.90,6.40]$ & 2012 & & & \\
\hline Chang KP & 1.1410 & 0.5335 & $10.4 \%$ & $3.13[1.10,8.91]$ & 2012 & & & \\
\hline $\operatorname{Lim} R$ & 0.7608 & 0.3213 & $28.7 \%$ & $2.14[1.14,4.02]$ & 2012 & & $\Longrightarrow-$ & \\
\hline Ryu IS & 1.5518 & 0.6658 & $6.7 \%$ & $4.72[1.28,17.40]$ & 2013 & & & \\
\hline \multicolumn{3}{|l|}{ Total $(95 \% \mathrm{Cl})$} & $100.0 \%$ & $3.14[2.24,4.40]$ & & & & \\
\hline \multicolumn{3}{|c|}{$\begin{array}{l}\text { Heterogeneity: } X^{2}=3.65, d f=5(P=0.60) ; 1^{2}=0 \% \\
\text { Test for overall effect: } Z=6.64(P<0.00001)\end{array}$} & & & & $0.05 \quad 0.2$ & 5 & 20 \\
\hline
\end{tabular}

FIGURE 5. Forest plots of HR for death with TLG.

for heterogeneity gave no significant results $\left(\chi^{2}=3.59, P=0.73 ; \mathrm{I}^{2}=\right.$ $0 \%)$. The pooled HR of death was 2.36 (95\% CI, 1.48-3.77, $P=$ 0.0003). There was no evidence of significant statistical heterogeneity, [Table 3] with an $\mathrm{I}^{2}$ of $0 \%\left(\chi^{2}=0.09, P=0.96\right)$ (Table 3).

\section{DISCUSSION}

This meta-analysis evaluated the prognostic value of MTV or TLG for ${ }^{18}$ F-FDG PET in patients with HNC by determining the HR of EFS and OS of high values for MTV or TLG, compared with those of low values for MTV or TLG. In combined results, patients with a high MTV showed a 3.06-fold-higher risk of adverse events or 3.51-fold-higher risk of death than patients with a low MTV. Patients with a high TLG had a 3.10-fold-higher risk of events or a 3.14-fold-higher risk of death than patients with a low TLG. Although large variability may affect MTV or TLG, our findings suggest that volumetric parameters of PET have prognostic value in EFS or OS. To evaluate the effects of methods selected in each study, we performed subgroup analyses, which

TABLE 3

Pooled HRs of Parameters

\begin{tabular}{lcccc}
\hline Endpoint & Parameter & HR & $95 \% \mathrm{Cl}$ of HR & $P$ \\
\hline EFS & SUVmax & 1.83 & $1.39-2.42$ & $<0.0001$ \\
& MTV & 3.06 & $2.33-4.01$ & $<0.00001$ \\
& TLG & 3.10 & $2.27-4.24$ & $<0.00001$ \\
OS & SUVmax & 2.36 & $1.48-3.77$ & 0.0003 \\
& MTV & 3.51 & $2.62-4.72$ & $<0.00001$ \\
& TLG & 3.14 & $2.24-4.40$ & $<0.00001$ \\
\hline
\end{tabular}

showed small variations of the HRs of EFS for MTV (2.75-3.68) despite the wide range of MTV $\left(11.2-45 \mathrm{~cm}^{3}\right)$.

Most previous studies that evaluated the prognostic value of volumetric parameters followed the protocol shown in Figure 6. [Fig. 6] First, the VOI is determined whether for tumors alone or tumors plus LN. Next, VOI is delineated with variable methods. The choice of the threshold may affect the absolute value of MTV or TLG (26). A certain SUV such as $2.5,3.0$, or percentages of SUVmax are widely used to properly differentiate between benign and malignant lesions (3). All voxels containing SUVs above these thresholds are measured as VOIs. The ranges of fixed SUV and percentage of SUVmax for VOI determination included in this study were limited to an SUV of 2.5-3.0 and 30\%-50\% of SUVmax. Also, a fixed SUV of 2.5 was adopted in 9 of 15 studies in this metaanalysis, which may be a good standard of thresholds of VOI delineation. The gradient segmentation method can also be used to delineate tumors. This method calculates spatial derivatives along the tumor radii and defines the tumor edge on the basis of derivative levels and continuity of the tumor edge (27). Manual drawing methods can be used to delineate VOIs; however, interobserver variability is possible. As a consensus has yet to be reached, MTV and TLG may range widely even in the same tumor, according to the method used. After the VOI is delineated, MTV or TLG or both are measured. Currently, commercially available tools for tumor analysis can enable more rapid and easier measurement of volumetric parameters (3). MTV or TLG are incorporated into categoric data using specific cutoff values. Patients are divided into 2 groups of high or low volumetric parameters (MTV or TLG). Cutoff values are determined mostly by the minimum $P$ value, ROC, or a median value. Although the minimum $P$ value method has widely been used in previous studies, it is associated with high false-positives and may yield a biased, unreliable, and nonreproducible estimate of the prognostic impact of the tested covariate (28). The cutoff values of studies included in this metaanalysis ranged widely according to the methods selected in each study, from 7.7 to $45 \mathrm{~cm}^{3}$ for MTV and from 55 to 330 for TLG. A few studies evaluated prognostic values of MTV or TLG with continuous variables without dividing patients into 2 groups (7). After patients were divided into 2 groups, the prognostic values of MTV or TLG were analyzed using the log-rank test or Cox proportional hazards regression method.

Ten previous meta-analyses of HNC with PET were identified by electronic searches of MEDLINE and EMBASE (Table 4). [Table 4] Eight studies analyzed the diagnostic performance of PET regarding LN metastasis $(29,30)$, distant metastasis (31-34), and residual disease or recurrence $(35,36)$. Prognostic values of SUVmax in terms of disease-free survival, OS, or locoregional control with the effect size of risk ratio or odds ratio were evaluated in studies by Zhang et al. (37) and Xie et al. (38). As the odds ratio is measured at a single point in time, it is not recommended as a surrogate 


\section{Delineation}

1. Volume of interest (tumor:lymph nodes)

2. Thresholds

1) Fixed SUV

2) Percentage of SUVmax

3) Gradient segmentation

Measurement of volumetric parameters

1. Metabolic tumor volume

2. Total lesion glycolysis

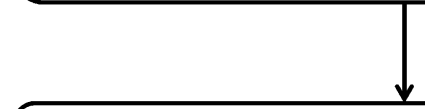

Determining cutoff values

Dividing into 2 groups (high/low)

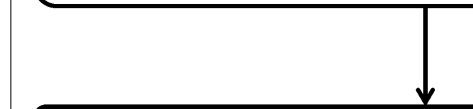

Statistical analysis

FIGURE 6. General protocol for analyzing volumetric parameters.

method for analyzing time-to-event outcomes (39); HR is the most appropriate measure. Therefore, we calculated the HR as the effect size of the current study. To the best of our knowledge, this is the first meta-analysis to evaluate the prognostic value of MTV or TLG in any kind of tumors. Although we analyzed HRs of SUVmax for events and deaths, comparison of HRs between SUVmax and volumetric parameters could not be done directly. However, pooled HRs of MTV and TLG seem to be higher than SUVmax for both EFS and OS, which might lead to the assumption that MTV and TLG are stronger predictors. In addition, SUVmax was not a significant prognostic factor either for EFS (6/7 studies) or for OS (2/3 studies) in most studies.

This study has several limitations. Regardless of the methods selected in each study, high values for MTV or TLG are shown to be associated with a higher risk of adverse events or death. However, as there is still debate over the best approach for VOI and threshold methods, we were unable to propose an optimal cutoff value to categorize volumetric parameters as high or low. Because we could not access individual patient data, there is a risk of bias in this study. Although we have found that patients with a high MTV or TLG had higher risk of adverse events or death than patients with a low MTV or TLG, there is the difficulty in interpreting the HRs for MTV and TLG, which stems from the fact that we do not know the exact incidence rate for the events of interest over a given period of time. Further prospective studies combining incidence rate of diseases are needed. We searched databases that include only studies that have been published. A publication bias cannot be excluded, even if the funnel plot does not suggest clear evidence of it. In addition, HNC is a heterogeneous disease, and patients with different histologic grade, stages, and treatments were included in this meta-analysis, which can affect events occurring over the time and survival. To recommend PET as a routine test in $\mathrm{HNC}$, further studies regarding costeffectiveness and those comparing clinical benefits of PET with those of other modalities are required. Second, even though 2

TABLE 4

Previous Meta-Analyses of HNC

\begin{tabular}{|c|c|c|c|c|c|c|}
\hline Study & Year & Country & $\begin{array}{l}\text { No. of } \\
\text { studies }\end{array}$ & $\begin{array}{l}\text { No. of } \\
\text { patients }\end{array}$ & Classification & Effect size \\
\hline Yongkui et al. (29) & 2013 & China & 14 & 742 & $\begin{array}{l}\text { Pretreatment, staging, detection } \\
\text { of regional nodal metastasis }\end{array}$ & Sensitivity/specificity \\
\hline Xu et al. (31) & 2012 & China & 8 & 1,147 & $\begin{array}{l}\text { Pretreatment, staging, detection } \\
\text { of distant malignancies }\end{array}$ & Sensitivity/specificity \\
\hline Xu et al. (32) & 2011 & China & 12 & 1,276 & $\begin{array}{l}\text { Pretreatment, staging, detection } \\
\text { of distant metastases and } \\
\text { second primary cancers }\end{array}$ & Sensitivity/specificity \\
\hline Kyzas et al. (30) & 2008 & Greece & 32 & 1,236 & $\begin{array}{l}\text { Pretreatment, staging, detection } \\
\text { of cervical node metastases }\end{array}$ & Sensitivity/specificity \\
\hline Yi et al. (33) & 2013 & China & 17 & 2,912 & $\begin{array}{l}\text { Pretreatment, staging, detection } \\
\text { of bone metastasis }\end{array}$ & Sensitivity/specificity \\
\hline Xu et al. (34) & 2011 & China & 15 & 1,445 & $\begin{array}{l}\text { Pretreatment, staging, detection } \\
\text { of distant metastasis }\end{array}$ & Sensitivity/specificity \\
\hline Isles et al. (36) & 2008 & United Kingdom & 27 & 917 & $\begin{array}{l}\text { Posttreatment, follow-up, detection } \\
\text { of residual or recurrent disease } \\
\text { after chemoradiotherapy }\end{array}$ & Sensitivity/specificity \\
\hline Gupta et al. (35) & 2011 & India & 51 & 2,335 & $\begin{array}{l}\text { Posttreatment, follow-up, detection } \\
\text { of residual or recurrent disease } \\
\text { or metastasis }\end{array}$ & Sensitivity/specificity \\
\hline Zhang et al. (37) & 2010 & China & 8 & 495 & Prognosis, DFS/OS & Risk ratio \\
\hline Xie et al. (38) & 2011 & China & 26 & 1,415 & Prognosis, DFS/OS/LRC & Odds ratio \\
\hline
\end{tabular}


reviewers independently read survival curves, the strategy could not ensure complete accuracy of the extracted data. In addition, as non-English articles were excluded in this study, the potential impact of language bias should be considered.

\section{CONCLUSION}

MTV and TLG are accurate prognostic indicators of outcome in patients with HNC. Despite clinically heterogeneous HNC and the various methods adopted between studies, we can confirm that patients with a high MTV or TLG are at higher risk for adverse events or death.

\section{DISCLOSURE}

The costs of publication of this article were defrayed in part by the payment of page charges. Therefore, and solely to indicate this fact, this article is hereby marked "advertisement" in accordance with 18 USC section 1734 . No potential conflict of interest relevant to this article was reported.

\section{REFERENCES}

1. Paidpally V, Chirindel A, Lam S, Agrawal N, Quon H, Subramaniam RM. FDGPET/CT imaging biomarkers in head and neck squamous cell carcinoma. Imaging Med. 2012;4:633-647.

2. Park GC, Kim JS, Roh JL, Choi SH, Nam SY, Kim SY. Prognostic value of metabolic tumor volume measured by ${ }^{18} \mathrm{~F}-\mathrm{FDG}$ PET/CT in advanced-stage squamous cell carcinoma of the larynx and hypopharynx. Ann Oncol. 2013;24:208-214.

3. Moon SH, Hyun SH, Choi JY. Prognostic significance of volume-based PET parameters in cancer patients. Korean J Radiol. 2013;14:1-12.

4. Arslan N, Miller TR, Dehdashti F, Battafarano RJ, Siegel BA. Evaluation of response to neoadjuvant therapy by quantitative 2-deoxy-2-[ $\left.{ }^{18} \mathrm{~F}\right]$ fluoro-D-glucose with positron emission tomography in patients with esophageal cancer. $\mathrm{Mol}$ Imaging Biol. 2002;4:301-310.

5. Rahim MK, Kim SE, So H, et al. Recent trends in PET image interpretations using volumetric and texture-based quantification methods in nuclear oncology. Nucl Med Mol Imaging. 2014;48:1-15.

6. Davison J, Mercier G, Russo G, Subramaniam RM. PET-based primary tumor volumetric parameters and survival of patients with non-small cell lung carcinoma. AJR. 2013;200:635-640.

7. Higgins KA, Hoang JK, Roach MC, et al. Analysis of pretreatment FDG-PET SUV parameters in head-and-neck cancer: tumor SUVmean has superior prognostic value. Int J Radiat Oncol Biol Phys. 2012;82:548-553.

8. Xie P, Yue JB, Zhao HX, et al. Prognostic value of ${ }^{18}$ F-FDG PET-CT metabolic index for nasopharyngeal carcinoma. J Cancer Res Clin Oncol. 2010;136:883-889.

9. Berghmans T, Dusart M, Paesmans M, et al. Primary tumor standardized uptake value (SUVmax) measured on fluorodeoxyglucose positron emission tomography (FDG-PET) is of prognostic value for survival in non-small cell lung cancer (NSCLC): a systematic review and meta-analysis (MA) by the European Lung Cancer Working Party for the IASLC Lung Cancer Staging Project. J Thorac Oncol. 2008;3:6-12.

10. Pan L, Gu P, Huang G, Xue H, Wu S. Prognostic significance of SUV on PET/CT in patients with esophageal cancer: a systematic review and meta-analysis. Eur $J$ Gastroenterol Hepatol. 2009;21:1008-1015.

11. Zhao Q, Feng Y, Mao X, Qie M. Prognostic value of fluorine-18-fluorodeoxyglucose positron emission tomography or PET-computed tomography in cervical cancer: a meta-analysis. Int J Gynecol Cancer. 2013;23:1184-1190.

12. Parmar MK, Torri V, Stewart L. Extracting summary statistics to perform meta-analyses of the published literature for survival endpoints. Stat Med. 1998;17:2815-2834.

13. Higgins JP, Thompson SG, Deeks JJ, Altman DG. Measuring inconsistency in meta-analyses. BMJ. 2003;327:557-560.

14. Egger M, Davey Smith G, Schneider M, Minder C. Bias in meta-analysis detected by a simple, graphical test. BMJ. 1997;315:629-634.

15. Kim G, Kim YS, Han EJ, et al. FDG-PET/CT as prognostic factor and surveillance tool for postoperative radiation recurrence in locally advanced head and neck cancer. Radiat Oncol J. 2011;29:243-251.

16. Chung MK, Jeong HS, Park SG, et al. Metabolic tumor volume of $\left[{ }^{18} \mathrm{~F}\right]$-fluorodeoxyglucose positron emission tomography/computed tomography predicts short-term outcome to radiotherapy with or without chemotherapy in pharyngeal cancer. Clin Cancer Res. 2009;15:5861-5868.
17. Kao CH, Lin SC, Hsieh TC, et al. Use of pretreatment metabolic tumour volumes to predict the outcome of pharyngeal cancer treated by definitive radiotherapy. Eur J Nucl Med Mol Imaging. 2012;39:1297-1305.

18. Chang KP, Tsang NM, Liao CT, et al. Prognostic significance of ${ }^{18}$ F-FDG PET parameters and plasma Epstein-Barr virus DNA load in patients with nasopharyngeal carcinoma. J Nucl Med. 2012;53:21-28.

19. Chan SC, Chang JT, Lin CY, et al. Clinical utility of ${ }^{18}$ F-FDG PET parameters in patients with advanced nasopharyngeal carcinoma: predictive role for different survival endpoints and impact on prognostic stratification. Nucl Med Commun. 2011;32:989-996.

20. Dibble EH, Alvarez AC, Truong MT, Mercier G, Cook EF, Subramaniam RM. ${ }^{18}$ F-FDG metabolic tumor volume and total glycolytic activity of oral cavity and oropharyngeal squamous cell cancer: adding value to clinical staging. $J \mathrm{Nucl}$ Med. 2012;53:709-715.

21. Lim R, Eaton A, Lee NY, et al. ${ }^{18}$ F-FDG PET/CT metabolic tumor volume and total lesion glycolysis predict outcome in oropharyngeal squamous cell carcinoma. J Nucl Med. 2012;53:1506-1513.

22. Lee SJ, Choi JY, Lee HJ, et al. Prognostic value of volume-based ${ }^{18}$ F-fluorodeoxyglucose PET/CT parameters in patients with clinically node-negative oral tongue squamous cell carcinoma. Korean J Radiol. 2012;13:752-759.

23. Abd El-Hafez YG, Moustafa HM, Khalil HF, Liao CT, Yen TC. Total lesion glycolysis: a possible new prognostic parameter in oral cavity squamous cell carcinoma. Oral Oncol. 2013;49:261-268.

24. Ryu IS, Kim JS, Roh JL, et al. Prognostic value of preoperative metabolic tumor volume and total lesion glycolysis measured by ${ }^{18} \mathrm{~F}-\mathrm{FDG}$ PET/CT in salivary gland carcinomas. J Nucl Med. 2013;54:1032-1038.

25. Garsa AA, Chang AJ, DeWees T, et al. Prognostic value of ${ }^{18}$ F-FDG PET metabolic parameters in oropharyngeal squamous cell carcinoma. J Radiat Oncol. 2013;2:27-34.

26. Van de Wiele C, Kruse V, Smeets P, Sathekge M, Maes A. Predictive and prognostic value of metabolic tumour volume and total lesion glycolysis in solid tumours. Eur J Nucl Med Mol Imaging. 2013;40:290-301.

27. de Jong PA, van Ufford HM, Baarslag HJ, et al. CT and ${ }^{18}$ F-FDG PET for noninvasive detection of splenic involvement in patients with malignant lymphoma. AJR. 2009;192:745-753.

28. Altman DG, Lausen B, Sauerbrei W, Schumacher M. Dangers of using "optimal" cutpoints in the evaluation of prognostic factors. J Natl Cancer Inst. 1994;86:829-835.

29. Yongkui L, Jian L. Wanghan, Jingui L. ${ }^{18}$ FDG-PET/CT for the detection of regional nodal metastasis in patients with primary head and neck cancer before treatment: a meta-analysis. Surg Oncol. 2013;22:e11-e16.

30. Kyzas PA, Evangelou E, Denaxa-Kyza D, Ioannidis JP. ${ }^{18}$ F-fluorodeoxyglucose positron emission tomography to evaluate cervical node metastases in patients with head and neck squamous cell carcinoma: a meta-analysis. $J$ Natl Cancer Inst. 2008;100:712-720.

31. Xu G, Li J, Zuo X, Li C. Comparison of whole body positron emission tomography (PET)/PET-computed tomography and conventional anatomic imaging for detecting distant malignancies in patients with head and neck cancer: a metaanalysis. Laryngoscope. 2012;122:1974-1978.

32. Xu GZ, Guan DJ, He ZY. ${ }^{18}$ FDG-PET/CT for detecting distant metastases and second primary cancers in patients with head and neck cancer: a meta-analysis. Oral Oncol. 2011;47:560-565.

33. Yi X, Fan M, Liu Y, Zhang H, Liu S. ${ }^{18}$ FDG PET and PET-CT for the detection of bone metastases in patients with head and neck cancer: a meta-analysis. J Med Imaging Radiat Oncol. 2013;57:674-679.

34. Xu GZ, Zhu XD, Li MY. Accuracy of whole-body PET and PET-CT in initial M staging of head and neck cancer: a meta-analysis. Head Neck. 2011;33:87-94.

35. Gupta T, Master Z, Kannan S, et al. Diagnostic performance of post-treatment FDG PET or FDG PET/CT imaging in head and neck cancer: a systematic review and meta-analysis. Eur J Nucl Med Mol Imaging. 2011;38:2083-2095.

36. Isles MG, McConkey C, Mehanna HM. A systematic review and meta-analysis of the role of positron emission tomography in the follow up of head and neck squamous cell carcinoma following radiotherapy or chemoradiotherapy. Clin Otolaryngol. 2008;33:210-222.

37. Zhang B, Li X, Lu X. Standardized uptake value is of prognostic value for outcome in head and neck squamous cell carcinoma. Acta Otolaryngol. 2010;130:756-762.

38. Xie P, Li M, Zhao H, Sun X, Fu Z, Yu J. ${ }^{18}$ F-FDG PET or PET-CT to evaluate prognosis for head and neck cancer: a meta-analysis. J Cancer Res Clin Oncol. 2011;137:1085-1093.

39. Michiels S, Piedbois P, Burdett S, Syz N, Stewart L, Pignon JP. Meta-analysis when only the median survival times are known: a comparison with individual patient data results. Int J Technol Assess Health Care. 2005;21:119-125. 